\title{
FACTORS INFLUENCING THE RESPONSIVENESS OF MALE ORIENTAL FRUIT FLY, BACTROCERA DORSALIS, TO METHYL EUGENOL (3, 4 DIMETHOXYALYL BENZENE)
}

\author{
MMSC Karunaratne and UKPR Karunaratne \\ Department of Zoology, University of Sri Jayewardenepura, Nugegoda, Sri Lanka
}

Accepted: 4 June 2012

\begin{abstract}
The parapheromone, methyl eugenol (ME) (3, 4 dimethoxyalyl benzene), occurring in a variety of plant species, is the most effective known lure attracting the male oriental fruit fly, Bactrocera dorsalis (Hendel). Bioassays were carried out in a wind tunnel under laboratory conditions, to evaluate behavioural responses of male flies to seven concentrations of ME, diurnal pattern of male responsiveness and age of responsiveness to methyl eugenol and the factors influencing the responsiveness of males to ME. Attraction of male flies to ME was assessed by monitoring three behavioural parameters namely the number of flies performing upwind zigzagging anemotactic flights over at least $50 \mathrm{~cm}$ to the $\mathrm{ME}$ source, total number of flies landing on the source and the total number of flies moved into the upwind section of the wind tunnel after 20 minutes. The responsiveness of males to $M E$ in-

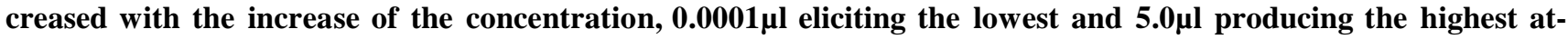
traction in males. All the males which were attracted exhibited a feeding response and no other behavioural response was observed. Male responsiveness to ME was not uniform throughout the day. The responses were highest during the morning $(82.6 \%)$, declined to a lower level in the afternoon $(\mathbf{4 1 . 8 \% )}$ ) and then dropped markedly at the 'dusk' period (11.4\%). This decline in response to ME suggested an inverse relationship to the time of peak mating activity in the male. Male responsiveness to $M E$ was found to be age-dependent. The response to the attractant increased with the age of the flies indicating a relationship between responses to $\mathrm{ME}$ and sexual maturity of the flies. No significant responses were evident when males were 1,3 and 5 days old. Males were strongly attracted to ME by the time they were 10d-old and the highest attraction was observed in 15d-old males. Attraction to ME was still considerably high even when they were 25 and $30 d-o l d$.
\end{abstract}

Key words: Bactrocera dorsalis, methyl eugenol, upwind anemotaxis, male responsiveness

\section{INTRODUCTION}

The powerful attraction exerted by certain chemical lures, particularly parapheromones (Sivinski and Calkins 1986) on some species of tephritid fruit flies including Bactrocera dorsalis (=Dacus dorsalis) is well known. Methyl eugenol (3, 4 dimethoxyalyl benzene), a phenylpropanoid compound (Nishida et al. 1988 ) is the most effective known lure attracting male oriental fruit flies. Howlett (1912) discovered the specific attraction properties of oil of citronella to males of Dacus (Bactrocera) spp. and subsequently, stated that methyl eugenol (ME) which is an ingredient of citronella oil was responsible for the attraction (Howlett 1915). Male Bactrocera species are very strongly attracted to blossoms, leaves or

\footnotetext{
*Corresponding author: punsisiravini@gmail.com
}

fruits of a variety of plants containing ME including flowers of Carica papaya L, mango species, Cassia fistula L, leaves of Melicope anasita Mann. and Colosia antiquorum L, (Metcalf et al. 1975). Tan and Nishida (2012) reported that more than 450 plant species contain varying amounts of $\mathrm{ME}$ in essential oils from leaves, roots, stems, flowers, or whole plant extracts.

ME has been shown to function as a precursor for the male sex pheromone in B. dorsalis and to increase the attractiveness of the pheromone to females (Nishida et al. 1988). It elicits strong anemotaxis in male flies and, in some species, equally strong chemotactic feeding responses (Meats and Osborne 2000). Steiner (1952) reported that ME is capable of attracting oriental fruit flies from as far as $0.8 \mathrm{~km}$. and described the characteristic and compulsive 
feeding behavior of the male fly. After ingestion, metabolites of ME is used in the synthesis of a sex pheromone (Nishida et al. 1988; Tan and Nishida 1996), subsequently making those males more attractive to females (Shelly 2000).

ME is widely used in monitoring programmes to detect early infestations of $B$. dorsalis (Chambers et al. 1974; Jang and Light 1996; Somerfield 1989) and for studies in population dynamics (Tan and Serit, 1994; Keawchoung et al. 2000). In addition, ME was used mixed with an insecticide to eradicate populations of oriental fruit flies successfully in several islands in the western Pacific via male annihilation (Steiner et al. 1965, 1970; Ushlo et al. 1982; Koyama et al. 1984). According to recent studies, there is a possibility of incorporating ME into sterile insect programs as a means to increase the mating competiveness of released, sterile males (Shelly 2010).

A number of observations published on the responses of male $B$. dorsalis to $\mathrm{ME}$ have been rather contradictory. Steiner (1952) reported that sexually immature males responded to ME. Wong et al. (1989) too proposed that $B$ dorsalis males were attracted to ME even before attaining sexual maturity. However, Fitt (1981b) reported that attraction of male $\mathrm{B}$. opilae, (a species very closely related to $B$. dorsalis) to ME commenced only after some days after emergence. This observation was reported by some other researchers as well (Umeya et al. 1973; Ibrahim and Hashim 1980). BriezeStegeman et al. (1978) reported that responsiveness of male $B$. opilae to ME was inversely related to the daily cycle of mating behaviour. The present study was therefore, commenced to gain a better understanding of the factors influencing responsiveness of male $B$. dorsalis to $\mathrm{ME}$ under laboratory conditions.

\section{MATERIALS AND METHODS}

Study Insects: Oriental fruit flies were reared in the laboratory by using the method similar to that of Mitchell et al (1965). The flies were maintained at a temperature of $29 \pm 2{ }^{\circ} \mathrm{C}$, and $78 \pm 2 \%$ relative humidity. A twelve hour light period of 1500lux provided by fluorescent lamps and attenuated light was supplied for one hour each at dawn and dusk (20lux). The adult flies were kept in wooden cages $(40 \times 28 \times 25 \mathrm{~cm})$ with Perspex front windows and a screen top. They were maintained on a diet consisted of dry sugar and water supplemented with small quantities of yeast hydrolysate. Adult male flies were separated within twenty four hours after emergence and kept in different cages for bioassays. They were provided with the same protein rich food.

Wind tunnel Bioassays: Factors affecting the responsiveness of male $B$. dorsalis flies were assayed in a wind tunnel made of clear plastic tubing, described by Karunaratne (1998). Adult male flies in a glass jar covered with gauze were placed at the downwind section of the wind tunnel a few minutes before the onset of each bioassay. ME applied into rubber bungs (treatment) by injecting the appropriate amount into the cavity by means of a microsyringe was placed at the upwind section of the tunnel to create a plume of odour. A rubber bung containing ME was placed in position immediately before the release of test flies. Average light intensity (average intensity of up, middle, and downwind sections) inside the plastic tunnel was kept at 1000-1050lux between 07:00 and 17:00h (daylight conditions) and 15-22 lux between 17:00 and 18:30h (dusk conditions). Air flow in the wind tunnel was regulated at $0.1 \mathrm{~m} / \mathrm{sec}$. Behavioural responses such as the number of flies performing upwind zigzagging anemotactic flights over at least $50 \mathrm{~cm}$ to the odour source (bung containing methyl eugenol), the total number of flies landing on the odour source and the total number of flies moved into the upwind section of the wind tunnel were recorded for 20 minutes.

Data Analysis: Each behavioural response monitored was considered separately and a one -way analysis of variance carried out. Where 
ever analysis of variance indicated a significant difference between responses to different treatments, Duncan's multiple range test (DMRT) was carried out at $\mathrm{p}=0.01$ level of significance to identify the significant treatments.

Behavioural activities of male flies in response to different concentrations of methyl eugenol: Seven concentrations of methyl eugenol $(0.0001,0.001,0.01,0.1,1.0,5.0$ and $10.0 \mu \mathrm{l}$ ) were tested against mature unmated male oriental fruit flies to study the effects on their behavioural responses. Twenty 10-13d-old males were tested in each treatment and replicated five times. The bioassay was conducted between 09:00-12:00h under daylight conditions.

Diurnal pattern of male responsiveness to methyl eugenol: To determine whether the male response to $\mathrm{ME}$ varied throughout the day, the responses of male $B$. dorsalis were assayed at approximately hourly intervals with 'daylight' and 'dusk' conditions. 5.0 $\mathrm{\mu l}$ of ME was tested against fifty 12-15d-old males with six replications for each treatment.

Effects of age on the male responses to methyl eugenol: Responses of male $B$. dorsalis to ME in relation to age were studied using the wind tunnel bioassay. 5.0 $\mu \mathrm{l} \mathrm{ME}$ was assayed against twenty males aged 1, 3, 5, 10, 15, 25 and 30d. Each observation was recorded between 09:00 and 12:00h under daylight conditions and five replicates were made for the flies of each age group.

\section{RESULTS AND DISCUSSION}

It is apparent from the results of the present study that ME responsiveness of males increased with the increase of concentration (Table 1). Highly significant differences were observed between the responses to the seven treatments as measured by the three behavioural parameters. The highest activities were recorded in response to $5.0 \mu \mathrm{l}$ dose whereas $0.0001 \mu 1$ of $\mathrm{ME}$ failed to elicit significant attraction in males. Only $4 \%$ males were attracted to the source when $0.01 \mu 1$ was tested. Metcalf et al. (1975) stated that the threshold for the feeding response of oriental fruit flies to $\mathrm{ME} 10^{-2} \mu \mathrm{g}$. Males responding to the chemical lure in the wind tunnel landed on the source and immediately began characteristic feeding behaviour.

The activities of male flies in response to $\mathrm{ME}$ were highest during the morning $(41.3 \pm 2.50$, declined to a lower level in the afternoon (20.8 \pm 3.0$)$ and then dropped markedly at the 'dusk' period $(5.7 \pm 1.3)$ at which time the mating activity of the flies usually occurs (Fig 1). The analyzed data indicated a sig-

Table 1. Behavioural activities of male flies in response to different concentrations of methyl eugenol

\begin{tabular}{llll}
\hline $\begin{array}{l}\text { Treat- } \\
\text { ment } \\
(\mu 1)\end{array}$ & $\begin{array}{l}\text { Upwind } \\
\text { anemotaxis }\end{array}$ & $\begin{array}{l}\text { No. landing } \\
\text { on the source }\end{array}$ & $\begin{array}{l}\text { Percentage } \\
\text { moved to up- } \\
\text { wind section }\end{array}$ \\
\hline Control & $1.4 \pm 0.3^{\mathbf{c}}$ & $0.4 \pm 0.2^{\mathbf{d}}$ & $13.2 \pm 5.1^{\mathbf{e}}$ \\
0.0001 & $1.0 \pm 0.4^{\mathbf{c}}$ & $\cdot 0.4 \pm 0.3^{\mathbf{d}}$ & $17.8 \pm 4.4^{\mathbf{d e}}$ \\
0.001 & $4.8 \pm 0.4^{\mathbf{b}}$ & $1.0 \pm 0.4^{\mathbf{c d}}$ & $32.0 \pm 2.8^{\mathbf{c d e}}$ \\
0.01 & $8.4 \pm 1.8^{\mathbf{b}}$ & $4.0 \pm 1.5^{\mathbf{b c}}$ & $40.8 \pm 1.7^{\mathbf{b c}}$ \\
0.1 & $15.8 \pm 2.3^{\mathbf{a}}$ & $6.6 \pm 0.9^{\mathbf{b}}$ & $45.4 \pm 3.1^{\mathbf{b c}}$ \\
1.0 & $17.4 \pm 1.6^{\mathbf{a}}$ & $12.4 \pm 2.0^{\mathbf{a}}$ & $67.0 \pm 8.2^{\mathbf{a b}}$ \\
& & & \\
\hline 10.0 & $19.6 \pm 0.9^{\mathbf{a}}$ & $16.8 \pm 1.1^{\mathbf{a}}$ & $81.8 \pm 4.9^{\mathbf{a}}$ \\
\hline
\end{tabular}

Mean values \pm standard error; Means in the same column followed by similar letters do not differ significantly $(p>0.01)$ 

EUGENOL

nificant effect of time on the responsiveness of males $(\mathrm{p}<0.005)$. Male responses did not differ significantly between 08:00h and $12: 00 \mathrm{~h}$ and the responses at dusk were significantly different from those of the rest.

Male oriental fruit flies were not uniformly attracted to ME throughout the day, but they responded most strongly in the earlier part of the day. The nature of the daily fluctuation in male responsiveness to ME suggests an inverse relationship with the daily cycle of their mating behaviour. The males were very active at dusk but extremely low numbers were attracted to ME source. Similar diurnal pattern of male responsiveness to $\mathrm{ME}$ has been reported for other fruit flies. Sexually mature fruit fly males such as B. cacuminata (BriezeStegeman et al. 1978), B. carambolae (Iwahashi et al. 1996) and B. opiliae (Fitt 1981b) show greatest response in the morning to mid-day. In all these species including $B$. dorsalis, mating activity is restricted to dusk, revealing marked temporal asynchrony between male responses to lures and mating rhythm.

All the behavioural activities recorded showed highly significant differences from those of the control (Table 2). Among the unmated males of $B$. dorsalis, the response to the attractant increased with the age. Young B. dorsalis males $(<3 \mathrm{~d}$ old), were not excited by or attracted to the ME source. When the

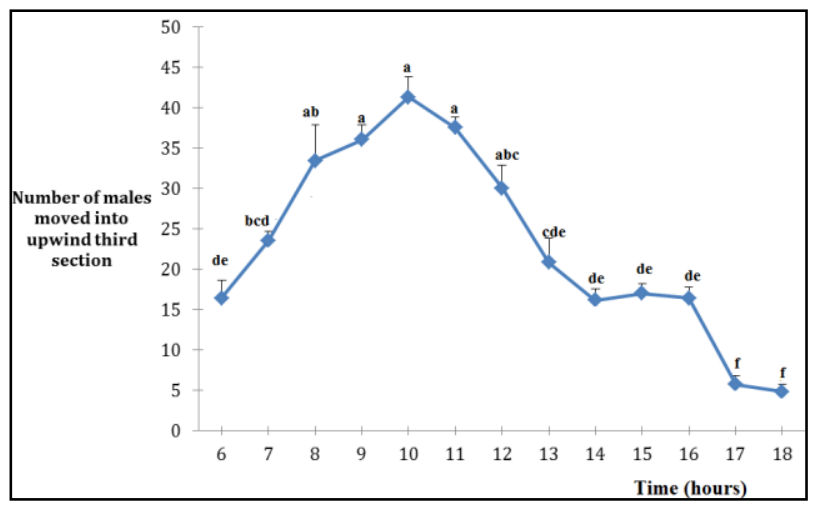

Figure 1: Diurnal pattern of male responsiveness to methyl eugenol (Mean \pm SE values of six replicates with 50 males in each replicate) males were 5d-old, only the number of their upwind anemotactic flights was significantly higher than the control, but there were very few landings on the source. Males were highly attracted to ME by the time they were $10 \mathrm{~d}$ old. The highest male responsiveness shown by all three parameters was observed in $15 \mathrm{~d}$ old males and the attraction was still fairly high even when they were $30 \mathrm{~d}$ old.

The development of male responsiveness to ME followed a similar profile to their sexual development. Under laboratory conditions, a majority of males attain sexual maturity when they are about 10d-old. The observations of the present study where newly emerged sexually immature males of $B$. dorsalis did not respond to $\mathrm{ME}$ differ from some of the previous findings. In fact, the studies published so far on the relationship between the responses to male lures and the age of the flies are conflicting. Steiner (1952) reported sexually immature B. dorsalis males (even as young as 1d-old) responded to ME. Similarly, Wong et al. (1989) stated both wild and laboratory reared oriental fruit flies responded to $\mathrm{ME}$, before they were sexually mature. Reexamining the relationship between sexual maturation and age of response to ME in male $B$. dorsalis in a recent study, Shelly et al. (2008) supported the conclusion made by Wong et al. (1989) that B. dorsalis males show attraction to, and feed on, ME before attaining sexual maturity. Nevertheless, they stated that the attraction is low among males that are 1-9 days old, and the attraction increases greatly between 9 and 15 days of age. Furthermore, they stressed the fact that although the strength of response varied among different age groups, males of all ages were captured in ME-baited Jackson traps in field cages.

However, in contrast to these observations, many other studies have indicated a close correlation between attraction to $\mathrm{ME}$ and sexual maturity in Bactrocera males. Umeya et al. (1973) observed that male fruit flies were not 
attracted to ME until the ninth day, suggesting that sexual maturity may play a prominent role. Similarly, Ibrahim and Hashim (1980) reported low attraction of 4 day old male oriental fruit flies to ME. Tan et al. (1986) in their studies observed that male oriental fruit flies at three days or less were not attracted to ME. A similar age-dependent increase in response to $\mathrm{ME}$ has also been reported for males of $B$. opiliae (Fitt 1981b) and $B$. carambolae (Wee \& Tan 2000). These observations accord well with the present study. The knowledge of physiological age of flies that are responsive to ME is vital in planning, monitoring and control programmes of fruit flies where this attractant is incorporated.

Table2: Responses of male $B$. dorsalis with different maturity (in days) to methyl eugenol

\begin{tabular}{|c|c|c|c|c|}
\hline \multirow{2}{*}{$\begin{array}{l}\text { Age } \\
\text { (d) }\end{array}$} & \multirow{2}{*}{$\begin{array}{l}\text { Treat- } \\
\text { ment }\end{array}$} & \multicolumn{3}{|c|}{ Response } \\
\hline & & $\begin{array}{l}\text { Upwind } \\
\text { anemotaxis }\end{array}$ & $\begin{array}{l}\text { No. landing } \\
\text { on the } \\
\text { source }\end{array}$ & $\begin{array}{l}\% \text { moved } \\
\text { to upwind } \\
\text { section }\end{array}$ \\
\hline \multirow[t]{2}{*}{1} & $\mathrm{C}$ & $0.8 \pm 0.3^{\text {cd }}$ & $0.0^{\mathrm{c}}$ & $5.8 \pm 2.7^{b}$ \\
\hline & $\mathrm{T}$ & $1.0 \pm 0.3^{\mathrm{cd}}$ & $0.0^{\mathrm{c}}$ & $9.0 \pm 1.4^{\mathbf{b}}$ \\
\hline \multirow[t]{2}{*}{3} & $\mathrm{C}$ & $0.4 \pm 0.2^{\mathrm{d}}$ & $0.0^{\mathrm{c}}$ & $9.6 \pm 2.3^{b}$ \\
\hline & $\mathrm{T}$ & $1.0 \pm 0.2^{\mathrm{cd}}$ & $0.4 \pm 0.2^{\mathrm{c}}$ & $9.0 \pm 2.9^{\mathbf{b}}$ \\
\hline \multirow[t]{2}{*}{5} & $\mathrm{C}$ & $0.4 \pm 0.2^{\mathrm{d}}$ & $0.0^{\mathrm{c}}$ & $7.6 \pm 1.9^{b}$ \\
\hline & $\mathrm{T}$ & $2.8 \pm 0.6^{\mathrm{c}}$ & $0.8 \pm 0.3^{\mathbf{c}}$ & $15.2 \pm 3.6^{\mathbf{b}}$ \\
\hline \multirow[t]{2}{*}{10} & $\mathrm{C}$ & $0.6 \pm 0.3^{d}$ & $0.4 \pm 0.2^{\mathrm{c}}$ & $10.2 \pm 4.0^{b}$ \\
\hline & $\mathrm{T}$ & $19.8 \pm 0.9^{\mathbf{a b}}$ & $13.6 \pm 1.5^{\mathrm{ab}}$ & $73.0 \pm 3.4^{\mathrm{a}}$ \\
\hline \multirow[t]{2}{*}{15} & $\mathrm{C}$ & $0.8 \pm 0.5^{\mathrm{cd}}$ & $0.8 \pm 0.5^{\mathbf{c}}$ & $12.2 \pm 1.8^{\mathbf{b}}$ \\
\hline & $\mathrm{T}$ & $25.8 \pm 2.3^{\mathrm{a}}$ & $14.8 \pm 0.6^{\mathrm{a}}$ & $76.0 \pm 5.2^{\mathrm{a}}$ \\
\hline \multirow[t]{2}{*}{25} & $\mathrm{C}$ & $0.6 \pm 0.3^{d}$ & $0.0^{\mathrm{c}}$ & $13.4 \pm 3.6^{b}$ \\
\hline & $\mathrm{T}$ & $15.8 \pm 2.8^{\mathbf{b}}$ & $11.4 \pm 1.7^{\mathbf{b}}$ & $68.0 \pm 7.5^{\mathrm{a}}$ \\
\hline \multirow[t]{2}{*}{30} & $\mathrm{C}$ & $0.6 \pm 0.3^{d}$ & $0.0^{\mathrm{c}}$ & $13.2 \pm 1.6^{\mathbf{b}}$ \\
\hline & $\mathrm{T}$ & $15.2 \pm 0.6^{\mathbf{b}}$ & $11.0 \pm 1.5^{\mathbf{b}}$ & $67.0 \pm 5.2^{\mathrm{a}}$ \\
\hline
\end{tabular}

Mean values \pm standard error; Means in the same column followed by similar letters do not differ significantly (p>0.01); C-Control; T-Treatment

\section{CONCLUSION}

The responsiveness of male Bactrocera dorsalis to ME was dose-dependent, producing the highest attraction in males at the dose of 5.0 $\mu 1$. Male responsiveness to $\mathrm{ME}$ was not uniform throughout the day, eliciting the highest response during the morning, declining to a lower level in the afternoon and dropping to a very low level at the dusk period. This decline in response to ME suggested an inverse relationship to the time of peak mating activity in the male. Male responsiveness to $\mathrm{ME}$ was found to be age-dependent. The response to the attractant increased with the age of the flies signifying a relationship between responses to $\mathrm{ME}$ and sexual maturity of the flies. Significant responses were not evident when they were 1,3 and 5d-old. The highest attraction was observed when males were $15 \mathrm{~d}$-old.

\section{REFERENCES}

Brieze-Stegeman R, Rice MJ and Hooper GHS 1978 Daily periodicity in attraction of male Tephritid fruit flies to synthetic chemical lures. J. Aust. Ent. Soc. 17: 341-346.

Chambers DL, Cunningham RT, Lichty RW and Thrailkill RB 1974 Pest control by attractants: a case study demonstrating economy, specificity, and environmental acceptability. Bioscience 24:150-152.

Fitt GP 1981b The influence of age, nutrition and time of day on the responsiveness of male Dacus opiliae to the synthetic lure, methyl eugenol. Entomol. Exp. Appl. 30: 83-90.

Howlett FM 1912 The effect of oil of Citronella on two species of Dacus. Trans. Ent. Soc. Lond. 60:412-418.

Howlett FM 1915 Chemical reactions of fruit flies. Bull. Ent. Res. 6: 297-305.

Ibrahim AG and Hashim AG 1980. Efficacy of methyl eugenol for trapping D. dorsalis (Hendel). Pertanika 3(2): 108-112.

Iwahashi O, Syamusdin-Subahar TS and Sastrodihardjo S 1996 Attractiveness of methyl eugenol to the fruit fly Bactrocera carambolae (Diptera: Tephritidae) in Indonesia. Ann. Entomol. Soc. Am. 89: 653-660.

Jang EB and Light DM 1996 Olfactory semiochemicals of tephritids, pp. 73-90. In B. A. McPheron and G. J. Steck (eds.), Fruit fly pests: a world 
assessment of their biology and management. St. Lucie Press, Delray Beach, FL.

Karunaratne MMSC 1998 Anemotactic responses of the male oriental fruit fly Dacus dorsalis to 2,3,5 trimethyl pyrazine in a horizontal wind tunnel. Vidyodaya Journal 7: 23-32

Keawchoung P, Limohpasmanee V, Dokmaihom R, Imyim A and Meecheepsom S 2000 Field population studies of the oriental fruit fly, Bactrocera dorsalis (Hendel) for SIT Programme in Thailand. Area-wide Control of Fruit Flies and Other Insect Pests (ed. KH Tan): 601-605.

Koyama J, Teruya T and Tanaka K 1984 Eradication of the oriental fruit fly (Diptera: Tephritidae) from the Okinawa islands by a male annihilation method. J. econ. Ent. 77: 468-472.

Meats A and Osborne A 2000 Dose-related upwind anemotaxis and movement up odour gradients in still air in the presence of methyl eugenol by the wild tobacco fruit fly, Bactrocera cacuminata. Physiol. Ent. 25: 41-47.

Metcalf RL, Mitchell WC, Fukutot TR and Metcalf ER 1975. Attraction of the oriental fruit fly, Dacus dorsalis, to methyl eugenol and related olfactory stimulants Proc. Nat. Acad. Sci. 72 (7): 2501-2505.

Mitchell S, Tanaka N and Steiner LF 1965 Methods of mass culturing melon flies and oriental and Mediterranean fruit flies. USDA ARS: 22

Nishda R, Tan KH, Serit M, Lajis NH, Sukari, AM, Takahashi S and Fukami H. 1988. Accumulation of phenylpropanoids in the rectal glands of male Oriental fruit fly, Dacus dorsalis. Experientia 44: 534-536.

Shelly TE 2000 Flower-feeding affects mating performance in male oriental fruit flies Bactrocera dorsalis. Ecol. Ent. 25: 109-114.

Shelly TE, Edu J and McInnis D 2010 Prerelease consumption of methyl eugenol increases the mating competitiveness of sterile males of the oriental fruit fly, Bactrocera dorsalis, in large field enclosures. J. Insect Sci.10 (8): 1-16.

Sivinski J and Calkins CO 1986 Pheromones and parapheromones in the control of tephritids. Fla. Entomol. 69: 157-168.

Somerfield KG 1989 Establishment of fruit fly surveillance trapping in New Zealand. New Zealand Entomologist 12: 79-81.

Steiner LF 1952 Methyl eugenol as an attractant for oriental fruit fly. J. econ. Ent. 45: 241-248.

Steiner LF, Mitchell WC, Harris EJ, Kozuma TT and Fujimoto MS 1965 Oriental fruit fly eradication by male annihilation. J. econ. Ent. 58: 961 $-964$
Steiner LF, Hart WG, Harris EJ, Cunningham RT, Ohinata K and Kamakahi DC 1970 Eradication of the oriental fruit fly from the Mariana Islands by the methods of male annihilation and sterile insect release. J. econ. Ent. 63: 131-135.

Tan KH, Kirton LG and Serit M 1986 Age response of Dacus dorsalis (Hendel) to methyl eugenol in a wind tunnel and traps set in a village and its implication in population estimation. Int. Symp. Fruit Flies/CRETE: 425-432.

Tan KH, and Nishida R 1996 Sex pheromone and mating competition after methyl eugenol consumption in the Bactrocera dorsalis complex pp. 147-153. In B.A. McPheron and G.J. Steck (eds.), Fruit fly pests. St. Lucie Press, Delray Beach, Florida

Tan KH, Nishida R 2012 Methyl eugenol: Its occurrence, distribution, and role in nature, especially in relation to insect behavior and pollination. J. Insect Sci. 12 (56): 1-74.

Tan KH and Serit M 1994 Adult population dynamics of Bactrocera dorsalis (Diptera : Tephritidae) in relation to host phenology and weather in two villages of Penang Island, Malaysia. Environ. Ent. 23: 267-275.

Umeya KY, Sekiguchi KY and Ushio SI 1973. The reproductive ability of the oriental fruit fly, Dacus dorsalis (Hendel) and the response of adults to methyl eugenol. Jap. J. app. Ent. Zool. 17: 63-70.

Ushlo SK, Yoshloka K, Nakasu K and Waki K 1982 Eradication of the oriental fruit fly from Amami Islands by male annihilation (Diptera: Tephritidae). Jap. J. appl. Ent. Zool. 26:1-9.

Wee SL. and Tan KH 2000 Sexual maturity and intraspecific mating success of two sibling species of the Bactrocera dorsalis complex. Entomologia exp. Appl. 94: 133-139.

Wong TTY, McInnis DO, Ramadan MM and Nishimoto JI 1989 Relationship of sexual maturation rate to response of oriental fruit fly strains (Diptera: Tephritidae) to methyl eugenol. J. Chem. Ecol. 15: 1399-1405. 